\title{
TENDÊNCIAS DA PESQUISA EM FORMAÇÃO DE PROFESSORES
}

\author{
RESEARCH TENDENCIES IN TEACHER EDUCATION
}

ROMANOWSKI, Joana Paulin

joana.romanowski@gmail.com

Pontifícia Universidade Católica do Paraná

\begin{abstract}
RESUMO O objetivo do artigo é apontar indicações sobre as tendências das pesquisas que abordam a formação de professores. Para as reflexões e análises considera estudos sobre o estado em que se encontra a formação de professores no Brasil, realizados desde o final da década de 1980. Incluem na análise os estudos do tipo estado da arte e as pesquisas do tipo pesquisa ação. Como aporte teórico e metodológico, a elaboração desse texto se apoia na sistematização de Santos (2005) que estabelece, em termos didáticos, diferentes níveis de conhecimento, do nível descritivo ao nível compreensivo, passando pelo nível explicativo.
\end{abstract}

PALAVRAS-CHAVE: Pesquisa em Formação de Professores. Estado da Arte. Pesquisa em Educação.

ABSTRACT The objective of this article is to point out indications about the trends of researches on teacher education. The reflections and analysis considers studies on the state in which you are teacher education in Brazil, conducted since the late 1980s. Includes analysis studies the type and state of the art research type action research. As theoretical and methodological the development of this text is based on the systematization of Santos (2005) establishing in didactic terms, different levels of knowledge, at the descriptive level understanding, through the explanatory level.

KEYWORDS: Research in Teacher Education. State of Knowledge. Research in Education.

\section{INTRODUÇÃO}

A formação de professores constitui-se preocupação dos sistemas de ensino desde a institucionalização da escola pública no final do século XVIII. Essa escola foi originada na conjuntura de ideias liberais da revolução francesa, secularizada, e para o acesso por toda a população. A Escola Normal criada no mesmo período propunha formar professores qualificados em todos os gêneros de conhecimento na arte de ensinar. (SAVIANI, 2009; TANURI, 2000). 
No Brasil, um século depois nascia a Escola Normal com a finalidade de formar professores para a educação primária inspirada nos escola normal francesa. Embora constem dos registros das inspeções realizadas pelo poder público no sistema de ensino a falta de formação de professores, a formação pública se concretiza somente no século XX (WACHOWICZ, 1984).

A formação em nível superior, no curso de pedagogia e licenciaturas, como se sabe ocorre a partir da década de 1930. Ainda que incipiente, a ideia de pesquisa foi agregada à formação. A Escola Normal que formava o professor para a escola primária não seguida os padrões de realização de pesquisa, associada à cultura e à profissionalização, instituída na universidade.

O contexto de ideias renovadoras no âmbito da formação de professores foi fomentado de modo especial por Anísio Teixeira (SAVIANI, 2007), que funda o Instituto Nacional de Estudos e Pesquisas Educacionais - INEP, em 1937, como aponta Saviani (2007). O INEP insere em sua estrutura uma divisão encarregada de desenvolver pesquisas educacionais. O seu Decreto de criação contém, como atribuição, promover investigações no terreno da psicologia aplicada à educação, favorecendo a inserção da pesquisa no sistema de educação brasileiro.

Ressalta-se que a Revista Brasileira de Estudos Pedagógicos - RBEP, criada para publicar as pesquisas realizadas pelo INEP, na sua primeira fase, foi um veículo de informações sobre as políticas educacionais. Só a partir da década de 1980, é que a RBEP articula-se com a comunidade acadêmica com a publicação de artigos de pesquisa. (SAVIANI, 2012).

Destarte, a pesquisa da/na formação dos professores, realizada nos cursos universitários, e mesmo no curso normal secundário, somente assume relevância a partir da década de 1980. Nesse período, os debates em torno da pesquisa em formação de professores passaram a ocorrer em simpósios, reuniões, artigos, investigações, teses e dissertações. Um dos primeiros balanços sobre a pesquisa em educação no Brasil, realizado por Gouveia em 1971, ao examinar os estudos desenvolvidos por Centros de Pesquisas Regionais, vinculados ao INEP/MEC, aponta a realização de levantamento sobre a caracterização de professores e profissionais de ensino, quanto ao nível de qualificação, condições socioeconômicas, posição funcional e expectativas dos professores. Esses estudos são diagnósticos sobre a condição de formação. 
Outro artigo publicado pelos Cadernos de Pesquisa da Fundação Carlos Chagas, nessa mesma década, sobre as prioridades de pesquisa em educação, realizado por Franco e Goldberg (1976), indica a existência de um conjunto de 41 estudos sobre comportamento dos professores associados aos resultados do ensino. As autoras mencionam a falta de investigações sobre as condições de treinamento dos professores e destacam a necessidade de abordagem da questão. No exame das pesquisas cadastradas do INEP, no período de 1968 a 1973, a formação de professores e magistério correspondia a oito estudos $(3,83 \%)$. Além disto, ressaltam a relevância social dessas pesquisas. Em outro estudo feito por Feldens (1989) apresentado no V ENDIPE, realizado em Belo Horizonte, foram feitas indicações a respeito das contribuições e desafios da pesquisa sobre a formação de professores. (ROMANOWSKI, 2012).

O presente artigo tem como propósito apontar indicações sobre as tendências das pesquisas que abordam a formação de professores. Para as reflexões e análises considera estudos sobre o estado em que se encontra a formação de professores no Brasil, realizados desde o final da década de 1980, tais como Candau (1987), Lüdke (1994), Gatti (1997), Gatti e Barreto (2009), entre outros. Inclui os estudos do tipo estado da arte feitos por André e Romanowski (1999) sobre teses e dissertações defendidas nos programas de pós-graduação na década de 1990; os de Brzezinski e Garrido, (2006) que focalizam amostra de teses e dissertações defendidas no período de 1997 a 2002; Carvalho (1999) sobre formação continuada de professores nos periódicos de maior circulação; Brzezinski e Garrido (1999) que realizaram pesquisa sobre o levantamento dos temas abordados no GT Formação de Professores da ANPEd e Brzezinski (2009) que apresenta pesquisa sobre formação de profissionais da educação no GT 8/ ANPEd. E mais o estudo de André (2004) que focaliza um estudo comparativo entre os anos de 1992 e 2002 e de Jardilino e outros (2012) que analisam os trabalhos publicados em reuniões da ANPEd por diferentes GTs sobre formação de professores.

Outra vertente de pesquisa em formação de professores são as investigações de intervenção, do tipo pesquisa ação, realizadas por grupos de pesquisa, participantes dos Simpósios I e II de Pesquisadores sobre Formação de Professores, coordenados pelo GT 08 Formação de Professores da Associação 
Nacional de Pesquisa e Pós-Graduação em Educação - ANPEd. Essas pesquisas referem-se a estudos em que o professor ao participar do processo de investigação realiza sua formação, portanto contribuem para o desenvolvimento profissional dos professores.

No exame desse conjunto de estudos e pesquisas sobre formação de professores, que se inserem no sistema educacional brasileiro, é possível depreender que paralelo ao sistema de ensino insere-se um possível sistema de formação de professores, que abrange a formação inicial e continuada desenvolvida na esfera federal, estadual e municipal e privada. São cursos, propostas, projetos com a finalidade de realizar a formação de professores.

Soma-se, ainda, a contribuição da pesquisa no próprio processo de formação, contribuindo para o desenvolvimento profissional dos professores, vertente também considerada neste texto.

Como aporte teórico e metodológico, a elaboração desse texto se apoia na sistematização de Santos (2005) que estabelece, em termos didáticos, diferentes níveis de conhecimento, do nível descritivo ao nível compreensivo, passando pelo nível explicativo. Ressalta-se que, considerados os limites do texto, foi considerado um conjunto de estudos, mas não a totalidade, ainda que a análise persevere pela totalidade.

\section{PESQUISAS SOBRE OS CURSOS E MODALIDADES DE FORMAÇÃO DE PROFESSORES}

Os estudos sobre o sistema de formação de professores desenvolvidos, desde a década de 1980, são estudos que consideram cursos, modalidades e programas em nível nacional, direcionados à formação inicial e continuada de professores e profissionais da educação em geral.

Com efeito, as pesquisas sobre formação de professores, fomentadas pelos órgãos governamentais, pode ser de caráter nacional e/ou local. Os estudos nacionais assumem uma perspectiva de exame e avaliação das instituições, cursos e programas decorrentes das políticas educacionais, bem como propõem alternativas para esse sistema de formação de professores. 
As pesquisas locais, realizadas por grupos e/ou pesquisadores individuais, examinam pontualmente uma instituição, um curso, um programa, uma disciplina, quanto à organização, abordagem curricular, processo de formação desenvolvido e resultados obtidos. Essas pesquisas têm sido sistematicamente investigadas por pesquisadores, individualmente ou em grupos, em estudos do tipo estado da arte.

Na década de 1980, estudos sobre formação de professores amplamente difundidos tais como o realizado por Candau (1987) tinham como preocupação analisar a formação dos professores que cursavam os cursos de licenciatura. Esse estudo conhecido como novos rumos da licenciatura fez uma análise do modelo de formação desses cursos, examinando a origem da centralidade na transmissão dos conteúdos específicos a serem reproduzidos no exercício profissional pelos futuros professores. No entanto, para traçar novos rumos apontou pegadas na direção da renovação da formação para a valorização da docência a partir do ensino dos conhecimentos específicos, em que as multidimensionais do conhecimento, interdisciplinares, de institucionalização da pesquisa e articulação com a escola básica, formem unidade referencial.

O estudo de Lüdke (1994, p. 2), demandado pelo Conselho de Reitores das Universidades Brasileiras - CRUB, fez uma análise das inovações nos cursos de licenciatura, "uma análise dos problemas mais cruciais que envolvem esses cursos e de experiências inovadoras que porventura tentam concretizar alternativas de solução para os problemas dos cursos de licenciaturas". Aponta em nível nacional quais as iniciativas desses cursos para processos diferenciados de formação.

Gatti (1997) realizou estudo solicitado pela Comissão de integração Universidade - Sistemas de Ensino, do Conselho Nacional de Secretários de Estado da Educação (CONSED). O propósito foi uma análise do panorama sobre a formação dos professores da educação básica, na época nominada de $1^{\circ}$ e $2^{\circ}$ graus. A abordagem incluiu o estado quantitativo de funções docentes e a titulação desses professores, bem como indicadores de número de matrículas e de concluintes dos cursos de habilitação de magistério e de licenciaturas. Sobre a formação nesses cursos o estudo realiza uma análise em torno da qualidade, apontando questões que perpassavam as condições institucionais, do currículo e 
das práticas formativas. Ainda, foram contempladas as condições de carreira e salário dos professores apontando para a não atratividade da profissão. Finaliza o estudo uma reflexão prospectiva apontando um quadro de mudanças necessárias para o enfrentamento das questões.

Pesquisa recente coordenada por Gatti e Barreto (2009), agenciada pela UNESCO e pelo MEC, com o propósito de realizar um balanço da situação relativa à formação de professores para a educação básica no Brasil, destaca a ampliação da oferta de cursos de licenciaturas tanto nas instituições públicas federais e estaduais e instituições privadas, com predomínio de cursos noturnos. A oferta de cursos na modalidade a distância cresce acentuadamente desde os anos de 1990 e examina os currículos dos cursos de licenciatura e os estudantes que realizam os cursos de licenciatura. Inclui a formação continuada quanto às propostas e modalidades, bem como os propósitos. O estudo finaliza com carreira e salário de docentes da educação básica.

Em relação às políticas de formação de professores, um estado da arte publicado em 2011, organizado por Gatti, Barreto e André, também agenciado pela UNESCO e MEC, analisa políticas relativas à formação inicial e continuada de professores, à carreira, ingresso, progressão e avaliação. O estudo apresenta questões sobre financiamento, reestruturação de órgãos governamentais, programas e projetos desenvolvidos em esfera federal, tais como Universidade Aberta do Brasil, o Plano Nacional de Formação de professores da Educação Básica, PARFOR, Programa Pró-Letramento entre outros. Inclui programas realizados em nível de secretarias de estados da federação, por região. Expressa ainda o quadro de renumeração e da carreira docente. Destaca programas de acompanhamento do ingresso dos professores na carreira.

Ainda nessa perspectiva de estudos de abrangência de largo espectro, o estudo sobre a atratividade da carreira docente, com assessoria geral de Gatti (2009), teve por finalidade examinar se os egressos do ensino médio optam pela carreira docente. Esse estudo foi demandado pela Fundação Carlos Chagas e contou com apoio de outras instituições.

Estudos interinstitucionais e/ou de temáticas específicas têm sido realizados por grupos de pesquisadores vinculados ao Programa de Observatório da Educação. No último edital, 2012, foram aprovados sete observatórios que 
incluem a formação de professores como foco de estudo, entre os quais, por exemplo: Os fatores de acesso e permanência que envolve a formação docente na UFRGS e seus contrastes com as expectativas e demandas do mundo do trabalho em escolas públicas da rede básica no estado do RS (UFRGS) e Projeto OBEDUC - formação de professores indígenas Guarani e Kaiowá em Mato Grosso do Sul: relações entre territorialidade, processos próprios de aprendizagem e educação escola.

No exame das teses e dissertações sobressaem os estudos locais, que pontualmente analisam o estado em que se encontra um curso, currículo, programa, disciplina. O ponto de partida da escolha do objeto a ser investigado vincula-se à prática que o pesquisador realiza. São pesquisadores que investigam o curso em que atuam como professores, cursos normais de nível médio, licenciaturas, pedagogia e programas de formação continuada. As pesquisas, geralmente, são diagnósticas do tipo levantamento empíricas analíticas, das quais decorrem como resultados apontamentos da situação, indicando especialmente os conflitos, inconsistências existentes nesses cursos e programas. Inclui a reformulação dos cursos, os conhecimentos abordados nas disciplinas, as práticas e processos, as aprendizagens, concepções, representações de professores e de alunos. A preocupação envolve a formação inicial e continuada de professores para a educação básica, educação infantil, fundamental e ensino médio, a educação superior, a educação profissional. A partir dos indicadores obtidos nas análises apresentam proposições alternativas para superação e mudança. (ANDRÉ, ROMANOWSKI, 2002; BRZEZINSKI, 2006; ANDRÉ, 2010; ROMANOWSKI; MARTINS, 2010).

\section{PESQUISAS DO TIPO ESTADO DA ARTE}

Destaca-se que a formação de professores como objeto de estudo, em teses e dissertações, desde $1987^{1}$, é constante e crescente quantitativamente. Naquele ano de 1987 consta uma dissertação, do total de 260 em educação, defendida no Programa de Mestrado em Educação da PUCRJ, que teve como tema analisar as disciplinas de Didática e Estágio nos cursos de formação de

\footnotetext{
${ }^{1} \mathrm{O}$ banco de consulta de resumos da CAPES está disponível a partir desta data.
} 
professores de $1^{\mathrm{a}}$ a $4^{\mathrm{a}}$ série. Em 1988, consta no banco de teses da Capes duas dissertações sobre formação de professores, do total de 224 em educação: uma sobre os estudos adicionais em alfabetização realizados após o curso normal, defendida na UFRJ, e outra sobre a autonomia do professor de $1^{\mathrm{a}}$ a $4^{\mathrm{a}}$ série, defendida na PUCRJ. Em 1989, o banco indica uma tese de doutorado, do total de 274 em educação, que abordou o uso de computadores em cursos de formação de professores, e foi defendida na UFRJ.

A partir dos anos de $1990^{2}$, o número de trabalhos passou a ser superior a uma dezena, 32 nesse ano, e ampliando sucessivamente finalizando em 1999 com 96 trabalhos, correspondendo em média a $6,5 \%$ do total de trabalhos da área de educação. Na década seguinte, 2000 a 2009, o número passa de uma centena, 188 em 2000, aumentando para 446 em 2009. Em 2010 este número é de 403, e em 2011 soma 687 teses e dissertações sobre formação de professores. Esses indicadores apontam constante pesquisa sobre o tema, e em termos proporcionais na área de educação os índices apontam uma variação de $6 \%$ a $12 \%$ do total. A Tabela 1 apresenta o número de teses e dissertações defendidas em educação e formação de professores, de 1987 a 2011. Nos últimos anos verifica-se que outras áreas apresentam pesquisas sobre a formação de professores, que não estão indicadas nessa tabela.

Na década de 1990, foram realizados vários estudos do tipo estado do conhecimento na área de educação em colaboração entre o Instituto Nacional de Estudos e Pesquisas Educacionais (INEP), o Comitê dos Produtores de Informação Educacional (COMPED), associações de pesquisadores e instituições de pesquisas. Estes estados do conhecimento tomaram como tema de análise: currículo da educação básica; educação superior em periódicos nacionais; formação de professores; formação de profissionais da educação; alfabetização; políticas e gestão da educação; avaliação na educação básica; educação infantil; educação de jovens e adultos; juventude e educação; educação e tecnologia. A finalidade destes estudos foi indicar o processo de construção do conhecimento sobre determinado tema para indicar duplicações, contradições e especialmente

\footnotetext{
2 As teses e dissertações defendidas entre 1990 a 2003 foram amplamente estudadas nos trabalhos coordenados por André (2002), Brzezinski (2006), Andrade (2006). Os dados após 2003 foram obtidos no banco de resumos de teses e dissertações da CAPES, considerando consulta com apalavra chave formação de professores.
} 
as lacunas existentes.

Para a realização destes mapeamentos foram consideradas teses e dissertações defendidas nos programas de pós-graduação em educação, artigos em periódicos, trabalhos apresentados em eventos. $O$ foco de análise desses estudos incide sobre o objeto, problema e metodologia, procedimentos e instrumentos de investigação utilizada, bem como os aportes teóricos e metodológicos. Um segundo nível de análise possibilita indicar a finalidade, natureza, abrangência e abordagens em que se move a pesquisa constituindo ponto de partida para definir a composição e delimitação de uma área de conhecimento ${ }^{3}$.

Estados da arte sobre formação de professores foram realizados por Feldens (1989) que analisa as pesquisas dos anos de 1980. Os estudos de André (1999) abordam as teses e dissertações defendidas nos programas de pósgraduação na década de 1990; Carvalho (1999) realizou pesquisa sobre formação continuada de professores nos periódicos de maior circulação; Brzezinski e Garrido (1999) realizaram pesquisa sobre o levantamento dos temas abordados no GT Formação de Professores da ANPEd.

No X ENDIPE, realizado no Rio de Janeiro, André (2001) aponta que as pesquisas defendidas nos programas de pós-graduação priorizam estudos pontuais mantendo em aberto uma compreensão global da formação de professores. Em relação ao mesmo tema, André (2004) focalizou um estudo comparativo entre os anos de 1992 e 2002, em trabalhos de dissertações e teses dos cursos de doutorado e mestrado das cinco regiões brasileiras sobre "Formação de Professores no Brasil". Soma-se o estudo realizado na PUCSP, em 2003/2004 sob a coordenação da Professora Marli André, do qual participaram alunos do doutorado e do mestrado em educação (Psicologia da Educação). $\mathrm{O}$ estudo realizado por Brzezinski e Garrido (2006) focaliza amostra de teses e dissertações defendidas no período de 1997 a 2002. Posteriormente, Brzezinski (2009) apresenta pesquisa sobre formação de profissionais da educação no GT 8/ ANPEd.

${ }^{3}$ Utiliza-se a categoria área por ser a o conceito empregado pelo CNPQ. 
Para a análise das teses e dissertações sobre o tema formação de professores, André e Romanowski (1999), Brzezinski e Garrido (2006) elegeram como categorias, no agrupamento das temáticas investigadas, indicadores da organização das modalidades de formação expressos na literatura e no modo de organização do sistema de ensino, considerando três temáticas: formação inicial, formação continuada, identidade e profissionalização docente. Em formação inicial estão inclusos os cursos de licenciatura, pedagogia, normal; em formação continuada: formação em serviço, propostas de mantenedoras, prática pedagógica. Identidade e profissionalização docente abarcam condições de trabalho, concepções de profissão, sindicatos e organização da categoria, gênero e identidade, e as teses e dissertações sobre prática pedagógica contêm estudos de vivências, saberes e reflexão.

O estudo feito por Carvalho e Simões (1999) agrupou os artigos por temáticas: formação inicial, formação continuada e identidade e profissionalização docente, e prática pedagógica. Brzezinski e Garrido (1999), ao considerarem os trabalhos apresentados no GT 08 Formação de Professores da ANPEd, agruparam as temáticas dos textos em tono de formação inicial, formação continuada, identidade e profissionalização docente, prática pedagógica, revisão de literatura.

Em Brzezinski e Garrido (2006) a análise das teses e dissertações, na viragem do século 1997 a 2002, assume como formação e profissionalização docente agrupados em Concepções de Docência e de Formação de Professores; Políticas e Propostas de Formação de Professores; Formação Inicial; Formação Continuada; Trabalho Docente; Identidade e Profissionalização Docente e Revisão de Literatura.

O estado da arte de teses e dissertações defendidas entre 1999 a 2003 feito por Andrade (2006) considerou como grupos temáticos: formação inicial, formação continuada, identidade e profissionalização docente, políticas de formação e formação inicial e continuada entendida como a que articula a experiência e a formação acadêmica típica de estudos que abordam a formação do professor leigo.

Além das temáticas abordadas nas teses e dissertações foram relacionados os tipos de estudo referentes à metodologia de investigação. A 
metodologia de investigação tem sido alvo de análise exaustiva por André (2000, 2002, 2007, 2009, 2010) e Lüdke $(2010,2012)$. Nessas análises são apontadas a variação, o modo e a densidade com que o processo de investigação se constitui pesquisa em formação de professores. Ressalta-se que a investigação em formação de professores torna-se mais aprofundada e inclui processos específicos tais como: depoimentos, (auto) biografias, pesquisas colaborativas e a pesquisa-ação. Conforme André (2010, p. 179/180), "[...] o avanço das pesquisas é a combinação de diferentes formas de coleta de dados. Muitos pesquisadores associam a entrevista com o exame de documentos, outras vezes com questionário ou com observação". Tal variedade de fontes de coleta indica uma abordagem mais ampla das questões sobre formação de professores, o que traz maior riqueza para a área.

Ainda, estudos sobre trabalhos em eventos que incluem a formação de professores tais como as reuniões da ANPEd e do ENDIPE, como os de Brzezinski $(2002,2009)$ sobre o GT Formação; Jardilino (2010) que examina o trabalho sobre formação nos diferentes Gts da ANPEd; Terrazzan e Gama (2007) que se detiveram sobre as pesquisas em formação continuada de professores; Ventorim (2005), que investigou os trabalhos sobre professor pesquisador nos ENDIPEs. E sobre as pesquisa realizadas nos programas de pós-graduação foi feita análise apresentada em 2002 como trabalho encomendado na reunião anual da ANPEd, por Ramalho, Nuñez, Terrazzan e Prada.

No levantamento das pesquisas das linhas de pesquisa formação de professores dos programas de pós-graduação em educação, quatro temáticas foram priorizadas: Profissão Docente, Profissionalização, Desenvolvimento Profissional, Identidade, Prática Pedagógica e os Saberes Docentes. Destacam os autores que essas temáticas "são reveladores de uma tendência marcante na atualidade, que é a preocupação em defender e colocar o Professor no centro do processo de construção da sua profissão e do seu desenvolvimento profissional". (RAMALHO; NUÑEZ; TERRAZZAN; PRADA, 2002, p. 7).

No conjunto desses estudos destacam-se como vertentes de análise: (i) as temáticas abordadas nas pesquisas, trabalhos e artigos publicados; (ii) as abordagens metodológicas; (iii) exame na perspectiva de avaliação quanto aos níveis de organização, fundamentação e coerência metodológica, se atendem às 
exigências de pesquisa científica. Essas vertentes são inter-relacionadas entre si, compondo uma quarta vertente: (iii) definição e configuração do campo disciplinar da formação de professores.

O exame da produção de conhecimentos sobre a formação de professor permite apontar avanços na definição e configuração do campo formação de professores e permite também apontar os princípios orientadores das investigações. Outro ponto a considerar refere-se ao exame da perspectiva epistemológica que permite interrogar a natureza e a especificidade do conhecimento produzido nesse campo (Severino, 1991). Ainda, ao examinar as pesquisas em formação de professores permite indicar as contribuições sociais da pesquisa.

No aprofundamento da compreensão do campo, os Simpósios de Grupos de Pesquisa sobre Formação de Professores somam-se aos estados da arte, no exame rigoroso destas perspectivas. Em ambos sobressai o esforço na definição de limites ou fronteiras do campo de conhecimentos sobre formação de professores. Isto favorece clarificar o objeto que se estuda, distinguindo-o de outros campos, ainda que cada campo possa se inscrever na interface de outros campos que integram um sistema de conhecimentos mais vasto. $\mathrm{O}$ mesmo se passa no plano das diferentes ciências. Porém, sem clarificar o foco, podemos ter confusão ou sobreposição de temas e assuntos, o que empobrece o conhecimento e limita estabelecimento de relações entre os vários campos da ciência. Limites não são fechamentos. São escolhas de lentes que clarificam a visão - da parte e do todo (ANDRÉ; BRZEZINSKI; LUDKE; ROLDÃO, 2010).

\section{AS PESQUISAS DE INTERVENÇÃO}

Em formação de professores o movimento de associação entre pesquisa e ação docente se intensifica a partir da década de 1990. Ventorim (2012) considera que a vertente do professor pesquisador está articulada à abrangência da educação superior pensada a partir da indissociabilidade entre pesquisa, ensino e extensão. $\mathrm{Na}$ origem dessa tendência é conhecido Stenhouse, que ao criar o Centro de Pesquisa Aplicada à Educação (CARE), para romper com a 
repetição rotineira da ação docente, propõe a experimentação, avaliando novas possibilidades de o professor realizar o seu trabalho. (LUDKE, 2012).

Entre os tipos são mais usuais a pesquisa-ação, a pesquisa participante, e a pesquisa colaborativa, que favorecem a inserção do professor em grupos de pesquisa de modo a influenciar o desenvolvimento e o trabalho do professor.

Para André (2006, p. 56), o movimento entre ensino e pesquisa educacional, no Brasil, "[...] é bastante recente. Ganha força no final dos anos 1980 e cresce substancialmente na década de 1990, acompanhando os avanços que a pesquisa do tipo etnográfico e a investigação-ação tiveram nesse mesmo período". Penitente, Del-Masso e Castro (2012) destacam a relevância da pesquisa na formação dos professores, muitas são as de cunho qualitativo realizadas nas escolas, não somente por especialistas e acadêmicos ligados à educação, mas também por professores que, no exercício de suas funções, analisam e teorizam as observações sobre sua prática.

A inserção da pesquisa na formação do professor da educação básica ocorre por: (i) participação dos professores em projetos de investigação realizados por pesquisadores na escola; (ii) iniciativas dos professores para inclusão da pesquisa na prática docente; (iii) programas de formação continuada com a realização de pesquisa pelo professor; (iv) pesquisa na formação inicial.

\subsection{Participação dos professores em projetos de investigação realizados por pesquisadores na escola}

A participação de professores em projetos de pesquisa tem sido desenvolvida em inúmeros projetos por iniciativa de pesquisadores das universidades que contam com possibilidade de financiamento por agências de fomento. Ainda que não se constitua um levantamento exaustivo, os a seguir indicados são exemplos da inserção de professores em projetos de pesquisa, entre eles os realizados por Lüdke (2012) desde a década de 1990; Bueno, Catani, Sousa e Souza que abordam questões de memória e gênero; o uso de vídeos no ensino realizado por Garrido e Carvalho (1999); de crônicas Barolli et al; igualmente na relação do professor com as tecnologias Kenski, e Fazenda com professores da educação básica. É intensa a realização de pesquisas na 
formação de professores das áreas específicas. Entre estes grupos de pesquisa inserem-se os direcionados aos professores de Ciências realizados por Villani; na formação de professores de Física coordenados por Terrazzan; o Programa Interfaces da Formação em Línguas Estrangeiras que engloba os projetos Educação Continuada de Professores de Línguas Estrangeiras - EDUCONLE, entre outros. Muitas teses assumem como objeto de estudo o desenvolvimento de projetos desse tipo pesquisa.

Essas investigações visam trabalhar a formação de professores estimulando a pesquisa na busca da melhoria do ensino, implementando novos procedimentos, estratégias, recursos didáticos, novas tecnologias de forma contextualizada no cotidiano escolar.

\subsection{Iniciativas dos professores para inclusão da pesquisa na prática docente}

A realização de investigações sobre a pesquisa do professor no ensino é alvo de estudos que têm como preocupação conhecer a situação do componente pesquisa na realidade do dia a dia dos professores, quer dizer, é preciso examinar se a pesquisa está presente na prática cotidiana dos professores da educação básica, "já que, na academia, ele é considerado como indispensável para um trabalho docente autêntico, não meramente repetitivo e prescrito", conforme Lüdke (2012, p.635).

Nessa perspectiva é ainda incipiente a generalização dos resultados, tratase de um campo de pesquisa educacional aplicada e a relação entre as ciências e seu ensino é complexa, impõe novos desafios para a área educacional, pois este tipo de investigação é pouco. (DELIZOIKOV, 2004).

\subsection{Programas de formação continuada com a realização de pesquisa pelo professor}

Entre programas de formação continuada que incluem a realização de pesquisa pelo professor propostos por mantenedoras, o Projeto Escola \& Universidade, ofertado pela Secretaria Municipal de Educação de Curitiba desde 1998, é um programa que estimula os professores e gestores que atuam nas 
escolas para elaborarem e desenvolverem projetos que promovam a melhoria na qualidade do ensino. Para o desenvolvimento do projeto, os professores recebem bolsas auxílio, em média, anualmente, são ofertadas 2500 bolsas. Esse Projeto é operacionalizado em parceria com universidades que analisam, selecionam, classificam e orientam o desenvolvimento dos projetos em encontros mensais.

A análise desse programa realizada por Mendes (2008) aponta impasses que expressam pouca articulação ente a pesquisa e o desenvolvimento profissional docente, pois o programa cinge-se na inserção de atividades inovadoras para a sala de aula. Mantém o trabalho individualizado e as parcerias com as IES expressam contribuição restrita à orientação pontual na execução do projeto de pesquisa e na elaboração do relatório. A pesquisa ação limita-se à realização de práticas que dizem respeito a colocar em curso projetos de ensino, e não de pesquisa.

$\mathrm{Na}$ atualidade, estão em desenvolvimento programas de desenvolvimento profissional no âmbito das escolas, promovidos e apoiados pelas secretarias de ensino municipais e/ou estaduais autogerenciados que podem articular-se ao desenvolvimento de pesquisas. Esses programas podem contar com a parceria entre universidade e escola. (GATTI; BARRETO; ANDRÉ, 2011).

\subsection{Pesquisa na formação inicial}

A inserção da pesquisa na formação inicial trata de compreendê-la como elemento essencial na formação profissional do professor (ANDRÉ, 2006). Entre as possibilidades a pesquisa pode ser entendida eixo formativo integrando o projeto do curso em que o aluno recebe formação para a pesquisa e realiza pesquisa. $O$ trabalho de conclusão de curso se insere neste tipo de formação e os programas de bolsa de iniciação científica - PIBIC são exemplos desta perspectiva.

Segundo a autora, "há possibilidades dos docentes do curso de formação inserirem seus próprios temas e projetos de pesquisa nos programas das disciplinas" favorecendo a formação em pesquisa (ANDRÉ, 2006, p. 61).

$\mathrm{Na}$ atualidade, o PIBID - Programa Institucional de Bolsa de Iniciação à Docência, realizado no interior das universidades para promover a inserção dos estudantes no contexto das escolas públicas desde o início da sua formação 
acadêmica para que desenvolvam atividades didático-pedagógicas sob orientação de um docente da licenciatura e de um professor da escola, pode assumir alguma perspectiva de investigação. Várias pesquisas estão em andamento para análise deste programa com apresentação de primeiros resultados em eventos.

$\mathrm{Na}$ década de noventa, o Programa de Apoio às Licenciaturas PROLICEN, proposto pelo Ministério de Educação, em 1994, visava o aprimoramento e a revitalização dos cursos de licenciatura, promovendo a integração com o ensino público da educação básica. Constituía no fomento de bolsas destinadas aos estudantes de licenciatura que participassem de projetos coordenados por professores desses cursos. Os projetos tinham como característica a promoção de pesquisa e extensão.

O programa foi desenvolvido nos anos de 1994/1995 e foi extinto em 1996. Em levantamento nas páginas institucionais das universidades federais, foi localizada a continuidade de projetos de PROLICEN em seis instituições federais, em que alguns projetos assumiram o caráter de pesquisa.

Paradoxalmente, este programa e os projetos nele desenvolvidos têm uma contribuição importante na formação docente dos alunos que dele participam ao aproximar a universidade da escola de ensino fundamental e médio.

Além disso, favorecem uma melhoria performática na formação dos futuros professores e possibilitam a participação do licenciando em projetos de pesquisa. No entanto, este programa não se integrou ao conjunto de discussões em torno dos cursos de licenciatura e não se constituiu referencial na elaboração de uma nova proposição para os cursos de licenciatura (ROMANOWSKI; GISI; MARTINS, 2008).

\section{CONSIDERAÇÕES FINAIS}

A intensificação da pesquisa sobre formação de professores a partir dos anos de 1990 situa-se no contexto das relações sociais históricas, que colocam a educação como 'porta de acesso' ao conhecimento tecnológico e base da Terceira Revolução Industrial. Como aponta Torres (1995, p. 120) "a nova economia reclama por trabalhadores com grande capacidade de aprender a 
aprender, capazes de trabalhar em equipe não só de maneira disciplina, mas criativa".

$\mathrm{Na}$ perspectiva da valoração da educação na atual conjuntura, Bruno (2011) chama atenção: "O que é importante destacar aqui é que apenas o acréscimo das qualificações decorrente de uma formação mais complexa do trabalhador permite a introdução de inovações e garante que se trabalhe eficazmente com elas, viabilizando os ganhos de produtividade" ${ }^{4}$.

Nesse contexto, a demanda por mais formação é impulsionada, originando a necessidade de avaliar essa formação, e os elementos a relacionados, de onde a preocupação de órgãos governamentais e organizações sociais com a educação e os sistemas de ensino. Somam-se a esses determinantes as exigências da própria produção acadêmica.

Ainda que de modo introdutório, apontamentos entre as interações da pesquisa sobre formação de professores e o contexto em que ela se engendra são determinantes. A necessidade de avaliação da formação, cursos, programas, impulsiona a pesquisa.

Destarte, os problemas e temas de pesquisa no campo da formação demandam a partir das políticas e práticas nesse campo, quer dizer, a inserção de novos temas é originada de novas políticas, por exemplo, na década de 1990, muitas pesquisas elegeram os CEFAMs, Centro Específico de Formação e Aperfeiçoamento para o Magistério. Na medida em que as políticas em torno da formação do professor em nível médio se arrefeceram, o interesse por este tema na pesquisa diminui. $\mathrm{Na}$ atualidade, estão emergindo várias pesquisas sobre Programa Institucional de Bolsa de Iniciação à Docência - PIBID.

A demanda por melhoria da prática docente, tomando como referência uma melhor formação, como indicam Marcelo (1999), Imbernon (2009) e outros, estimulou vários grupos de pesquisa ação, participante, colaborativa. Enfim, investigações que colocam professores como colaboradores e investigadores de sua própria prática.

Além disto, outra demanda para a realização de pesquisas em formação de professores advém de novas proposições teóricas, isto é, novos processos em

\footnotetext{
${ }^{4}$ Cumpre destacar que no texto referido Bruno (2011) indica que essa imposição por formação não corre de modo linear. Alunos e professores expressam de vários modos formas de resistência.
} 
formação de professores inserem-se no meio acadêmico, como, por exemplo, a reflexibilidade, história de vida, formação pela pesquisa, entre outras, que geram novos temas de pesquisa. Essa perspectiva requer investigação para a compreensão dessas proposições nos processos de formação e desenvolvimento profissional dos professores.

Ainda, as atuais exigências de maior titulação profissional, como modo de ascensão na carreira, incentiva os profissionais da área a buscarem mestrados e doutorados. Isso origina maior número de teses e dissertações defendidas.

Igualmente, na última década, os estudos sobre delimitação e abrangência do campo de formação de professores constituíram foco de inúmeras investigações e continuam a exigir o debate. Essa demanda trouxe para exame a metodologia de investigação. Os estudos examinaram tanto as tendências das abordagens de pesquisa, bem como a adequação e pertinência dos procedimentos, instrumentos de pesquisa e da análise. Ressalta-se que, segundo André (2010), as investigações em formação de professores tiveram avanços metodológicos, mas ainda expressam fragilidades.

A intensificação da pesquisa sobre formação docente, embora permita uma maior compreensão das modalidades (cursos, programas), das políticas, das teorias que fundamentam o campo, bem como da própria pesquisa desenvolvida, exige continuidade de aprofundamento das reflexões e estudos. Os dilemas, entraves, fragilidades, condições em que se efetiva a formação e a pesquisa, são desafios tanto para os órgãos do sistema educacional, como para o campo de investigação.

Ao finalizar este texto, cabe indicar que a sua provisoriedade se expressa no limite da interpretação realizada, mas assume o caráter de penhora para a continuidade de entendimento do campo da formação de professores.

\section{JOANA PAULIN ROMANOWSKI}

Doutora em Educação - USP. Bolsa Produtividade em Pesquisa CNPQ, Professora do Programa de Pós-Graduação em Educação da Pontifícia Universidade Católica do Paraná e consultora pedagógica do Centro Universitário - UNINTER.

\section{REFERÊNCIAS}


ANDRADE, R. R. M. de. Formação de professores nas dissertações e teses defendidas em programas de pós-graduação em educação entre os anos de 1999 e 2003. PUC, Dissertação de Mestrado, 2006.

ANDRÉ, M. E. D. A. A Jovem Pesquisa Educacional Brasileira. Revista Diálogo Educacional (PUCPR), v. 06, p. 11-24, 2006.

ANDRÉ, M. E. D. A. Formação de professores: a constituição de um campo de estudos. Educação (PUCRS. Impresso), v. 33, p. 06-18, 2010.

ANDRE, M. E. D. A; BRZEZINSKI, I.; LUDKE, H. A. ; ROLDÃO, M. do C. Registro Sintético da Mesa Redonda no II Simpósio de Grupos de pesquisa sobre Formação de professores. In: II Simpósio de Grupos de pesquisa sobre Formação de professores, 2011, Curitiba. II Simpósio de Grupos de pesquisa sobre Formação de Professores. Curitiba: PUC PR, 2011. p. 336-341.

ANDRÉ, M. E. D. A. de; A pesquisa sobre formação de professores no Brasil, 1990-1998. In: ENCONTRO NACIONAL DE DIDÁTICA E PRÁTICA DE ENSINO, 10, 2000, Rio de Janeiro. Rio de Janeiro: 2000.

ANDRÉ, M. E. D. A. de; ROMANOWSKI, J. P. O tema formação de professores nas teses e dissertações brasileiras, 1990-1996. In: REUNIÃO Anual da ANPEd, 22., 1999, Caxambu (MG). Anais... Caxambu: ANPEd, 1999.

BRZEZINSKI, I. Formação de profissionais da educação no GT 8/Anped. : travessia histórica. Revista Brasileira de Pesquisa sobre Formação de Professores, v. 1, p. 1-5, 2009.

BRZEZINSKI, I. (org.). Formação de Profissionais da Educação (1997-2002). Brasília - MEC/ DF/Inep, 2006.

BRZEZINSKI, I; GARRIDO, E. Estado do conhecimento sobre formação de professores. Encontro com o que revelam os trabalhos do Gt formação de professores da ANPEd. Brasília: MEC/INEP/COMPEd, 1999.

CANDAU, V. (coord.). Novos rumos da licenciatura. In: Estudos e Debates 1 Brasília: INEP; Rio de Janeiro: PUC/RJ, 1988, 93p.

CARVALHO, J. M.; SIMÕES, R. H. S. O que dizem os periódicos brasileiros sobre a formação e práxis dos professores: 1990-1997. Vitória: Universidade Federal do Espírito Santo, Centro Pedagógico, Programa de Pós-Graduação em Educação, jul. 1999.

DELIZOICOV, D. Pesquisa em ensino de ciências como ciências humanas aplicadas. Caderno Brasileiro de Ensino de Física, v. 21, n. 2, p. 145-175, 2004. 
FELDENS, M. das G. F. A pesquisa em educação na formação de professores: contribuições e desafios. V Encontro de Didática e Prática de Ensino. Belo Horizonte, 1989.

FRANCO, M. L. P. e GOLDBERG, M. A. A. A pesquisa sobre educação no Brasil: de 1970 para cá. Cadernos de Pesquisa, São Paulo, n.19, p. 75-80, dez. 1976.

GATTI, B. A. et al. Atratividade da carreira docente no Brasil. In: Fundação Victor Civita. Estudos e pesquisas educacionais. São Paulo: FVC, 2010, v. 1, n. 1.

GATTI, B. A. e BARRETO, E. S. S. (coord.) Professores do Brasil: impasses e desafios. Brasília: UNESCO, 2009.

GATTI, B. A. Formação de professores e carreira: problemas e movimentos de renovação. Campinas: Autores Associados, 1997.

GATTI, B. A., BARRETO, E. S. S. e ANDRÉ, M. A. D., As Políticas Docentes no Brasil - um estado da arte. Brasília: UNESCO, 2011.

GOUVEIA, A. J. A pesquisa educacional no Brasil. Cadernos de Pesquisa. São Paulo, Fundação Carlos Chagas, n.1, p.p.1-48 1971. [online].

IMBERNON, F. Formação continuada de professores. Porto Alegre: ArtMed, 2009.

JARDILINO, J.; PASSOS, L. F; HOBOLD, M.; ANDRÉ, M. E. D. A.; DURAN, M. C. G. Contornos de um Campo de Pesquisa: considerações a partir da produção sobre Formação de Professores divulgada no GT 08 da ANPEd, 2000 - 2010. 34 Reunião da ANPED, 2011.

LÜDKE, H. A. Avaliação Institucional: Formação de docentes para o Ensino Fundamental e Médio: As Licenciaturas. $7^{\circ}$. ed. Brasília: Cadernos CRUB 4, 1994. v. $1.96 \mathrm{p}$.

LÜDKE, H. A. Desafios para a pesquisa em formação de professores. Revista Diálogo Educacional (PUCPR. Impresso), v. 12, p. 629-646, 2012.

PENITENTE, L. A. de A.; DEL-MASSO, M. C. S.; CASTRO, R. M. de. Processos de pesquisa e de estudo e a formação de professores: alguns aspectos teóricometodológicos. Revista Diálogo Educacional, Curitiba, v. 12, n. 37, p. 681-699, set./dez. 2012. 682.

RAMALHO, B.L, et.al. A pesquisa sobre a formação de professores nos programas de pós-graduação em educação: o caso do ano 2000. In. $25^{a}$ Reunião Anual da Anped, 2002. (trabalho encomendado Gt 08)

ROMANOWSKI, J. P Licenciaturas no Brasil: um balanço das teses e dissertações. 1. ed. São Paulo: USP, 2002. v. 1. 146 p.

ROMANOWSKI, J. P. Apontamentos em pesquisas sobre formação de 
professores: contribuições para o debate. Revista Diálogo Educacional (PUCPR), v.37, p.905 - 924, 2012.

ROMANOWSKI, J. P., MARTINS, Pura Lúcia Oliver. Situação atual das licenciaturas: o que indicam as pesquisas a partir de 2000 In: Convergências e tensões no campo da formação e do trabalho docente: didática, formação de professores, trabalho docente. $1^{\mathrm{a}}$ ed. Belo Horizonte: Autêntica, 2010, v.1, p. 509526.

SANTOS, O. J. Fundamentos sociológicos da educação. Belo Horizonte: FUMEC, 2005.

SAVIANI, D. Formação de professores: aspectos históricos e teóricos do problema no contexto brasileiro. Revista Brasileira de Educação. v. 14 n. 40 jan./abr. 2009.

SAVIANI, D. O Inep, o diagnóstico da educação brasileira e a Rbep. Revista Brasileira de Estudos Pedagógicos. v. 93, n. 234, [número especial], p. 291322, maio/ago. 2012.

SOARES, M.; MACIEL, F. P. Alfabetização no Brasil: o estado do conhecimento. Disponível em: http://www.mec.inep.gov.br. Acesso em março, 2013.

TANURI, L. História e formação de professores. Revista Brasileira de Educação. N 14, mai/ago, 2000.

TERRAZAN, E; GAMA, M.E. Características da formação continuada de professores nas diferentes regiões do país. In. 30 $^{\text {a }}$ Reunião Anual da Anped, 2007.

VENTORIM, S. A formação do professor pesquisador na produção científica dos encontros nacionais de Didática e Prática de Ensino: 1994-2000. In. $\mathbf{2 8}^{\mathrm{a}}$ Reunião Anual da Anped, 2005.

WACHOWICZ, L. A. Relação professor- estado no Paraná tradicional. São Paulo: Cortez Editora Autores Associados, 1984. 